\title{
The 33rd International Geological Congress, Oslo 2008
}

1 Norwegian Geotechnical Institute, P.O. Box 3930, Ullevål Stadion, NO-0806 Oslo, Norway. E-mail: Anders.Solheim@ngi.no

2 Geological Survey of Norway, NO-7491 Trondheim, Norway.E-mail: Arne.Bjorlykke@ngu.no

The 33rd International Geological Congress is being organised jointly by the Nordic countries and to be held in Oslo, Norway, August 6-14th, 2008. This "Geoscience World Congress 2008" will run up to 40 parallel science sessions, poster sessions, an extensive exhibition, short-courses, workshops, and business meetings; about 50 exciting pre- and post-Congress excursions are planned. The excursions include all the Nordic countries, as well as Greenland, Svalbard, the Faeroes, Russia and Ukraine. All major geoscientific themes are being covered by the Congress which has been divided into two parts, Sunday 10th August being without Symposia and dedicated to workshops, short courses, business meetings and excursions. Through a series of "Themes of the Day", seven themes with major societal impact will be covered in plenary sessions with invited lecturers, including a key-note "StatoilHydro lecture" given each day during the lunch interval. The venue is set up to offer a compact Congress with easy access to all sessions and other events. An extensive social and cultural programme is also being arranged.

\section{Introduction}

The International Geological Congress (IGC) was founded in 1876 and the first meeting was held in Paris in 1878. Thereafter, for more than 100 years, the IGCs have been the main global multidisciplinary platform for exchange of ideas and experience among geologists and other geoscientists. IGCs, taking place every four years, are the "Olympic Games" for geologists. The 33rd IGC will give the participants specialised symposia of high quality, presenting overview papers and thematic sessions for the geoscience community as well as society at large. Excursions have always been an important part of IGC and this tradition will be continued in Oslo 2008, with about 50 exciting excursions to choose from.

Over the years, the number of participants has gradually increased, from the initial 312 in Paris 1878, to the 7281 of the 32 nd IGC in Florence, Italy in 2004 (Abbate et al., 2005). The Nordic countries have hosted the Congress twice before, in Stockholm 1910 (Sunquist and Nordlund, 2004), and in Copenhagen 1960 (Sørensen, 2007). The five Nordic countries, Sweden, Denmark, Iceland, Finland, and Norway decided to join forces and announced their candidature at the congress in Rio de Janeiro in 2000. The formal bid was submitted in 2002 and the 33rd IGC was awarded to the Nordic Countries, during the 32nd Congress in 2004.

Arranging an International Geological Congress is a major challenge, and much work has been focussed on obtaining support of various kinds. The organisers of the 33rd IGC are honoured to have his Majesty the King of Norway as patron of the Congress. UNESCO has also offered its patronage, clearly demonstrating the importance of the Congress for society at large.
Two major international events are closely related to the Congress. The International Polar Year (IPY) runs from 2007 to 2009 , and with the Congress' strong emphasis on the Arctic, a close connection to IPY is natural. The International Year of Planet Earth (IYPE) was ratified by the UN General Assembly in 2005, and is also running in the period 2007-2009. The IYPE has chosen to focus on ten main themes, all with great societal importance. Several of these themes are also main themes of the Congress, and will be treated in full-day plenary sessions. Through these "Thematic Days", the 33rd IGC offers participants an overview of the state-ofthe-art in research, as well as an unique possibility to discuss their relevance and the impact on society. Together, they contribute to the main message of the Congress-Earth System Science: Foundation for Sustainable Development.

\section{Organisation}

A Nordic congress organisation structure (Figure 1) was set up to handle the preparations. The legal entity behind the Congress is a "Nordic Foundation for IGC". The foundation is registered in Norway and is led by a board with one member from each of the Nordic countries, appointed by the Academy of Sciences in each country. The 33rd IGC Organising Committee consists of 12 members: President, Secretary General, Vice-Presidents (VPs) for Science, Finance, Operations, Communication and International affairs, VPs for Iceland, Sweden, Finland, and Denmark, and a representative for the Congress' PCO, Congress-Conference AS in Oslo. Subcommittees have been organised under the various VP's areas of responsibility (Figure 1). Contact with the 32nd IGC Organising Committee in Italy was established early and the experience from the Florence Congress, as published in the 32nd IGC General Proceedings, has been of great value in the preparatory work.

The Organising Committee has spent much effort in obtaining sponsorship from external sources to keep the registration fees at a moderate level. Norway's biggest oil company, Statoil (now StatoilHydro), agreed at an early stage to be the Congess' main sponsor. Other companies form the petroleum sector, as well as companies from other fields, such as the Nordic mining industry, have provided financial support to the Congress. The Norwegian Government and the Research Council of Norway are also key sources of funding. Additional important support has come from the Nordic Council of Ministers and from other Nordic governments and research councils.

\section{The venue}

The venue chosen for the Congress is the Norway Convention Centre (Figure 2) at Lillestrøm, located $20 \mathrm{~km}$ east of Oslo City Centre. The venue consists of 4 main halls, as well as an attached hotel, which also holds lecture rooms. In addition to the existing, permanent and semi-permanent lecture halls, a set of temporary auditoriums will be built inside Hall D (Figure 2). Up to 40 oral sessions will run in parallel in lecture halls ranging in size between 80 and 500 seats. Hall B will be used for daily plenary sessions ("Themes of the Day"), whereas Hall $\mathrm{C}$ is allocated for the poster sessions and the exhibition, "GeoExpo 2008". The Convention Centre will also be 
33rd IGC Organisation

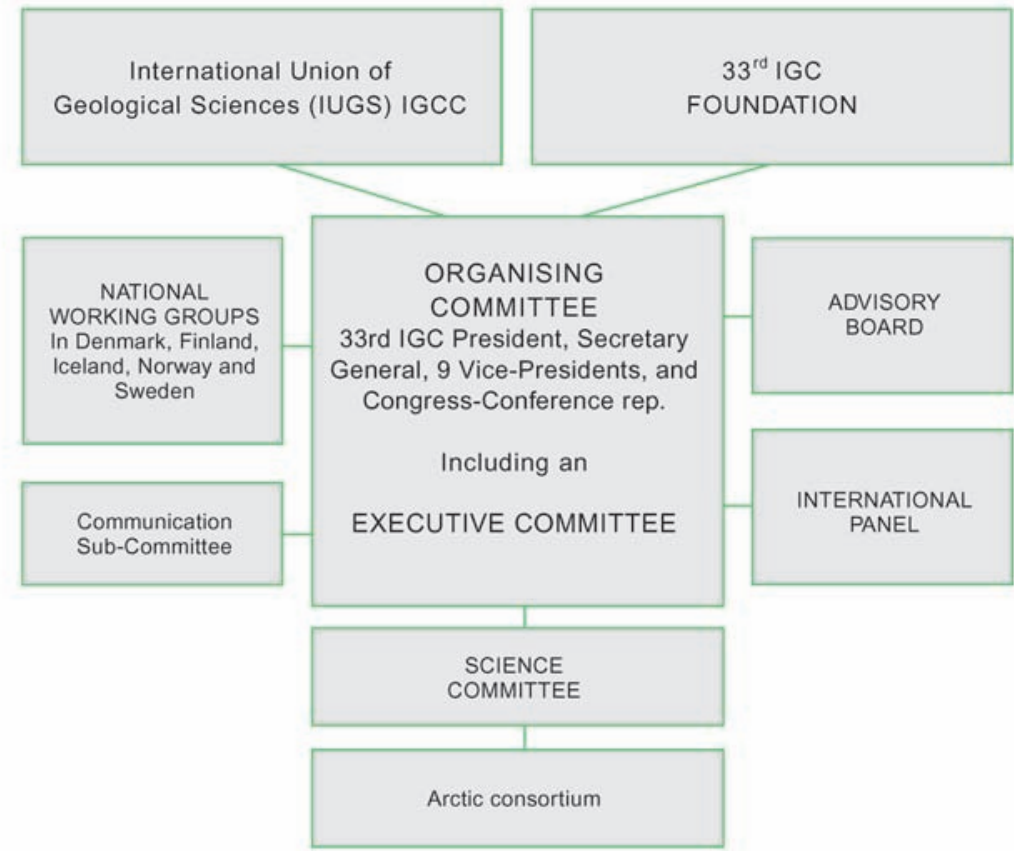

\section{3rd IGC Organising Committee}

President

Secretary General

VP International Relations

VP Finances

VP Science Programme

PCO Company Representative

VP Operations

VP Communications

VP for Denmark

VP for Sweden

VP for Finland

VP for Iceland

Science Programme Coordinator
Arne Biørlykke

Anders Solheim

Richard Sinding-Larsen

Finn Roar Aamodt

David Gee

Øivind R. Lie

Ellen Ramberg

Berit Forbord Moen

Johnny Fredericia

Olle Selinus

Elias Ekdahl

Kristinn J. Albertsson

Björn Sundquist
Geological Survey of Norway (NGU)

Norwegian Geotechnical Institute (NGI)

Norwegian University of Science and Technology (NTNU) Statoil ASA

Uppsata University, Sweden

Congress-Conference AS

Ramberg Consulting AS

Geological Survey of Norway (NGU)

Geological Survey of Denmark and Greenland (GEUS)

Geological Survey of Sweden (SGU)

Geological Survey of Finland (GTK)

University of Iceland

Uppsala University, Sweden

Figure 1 The 33rd IGC logistic structure.
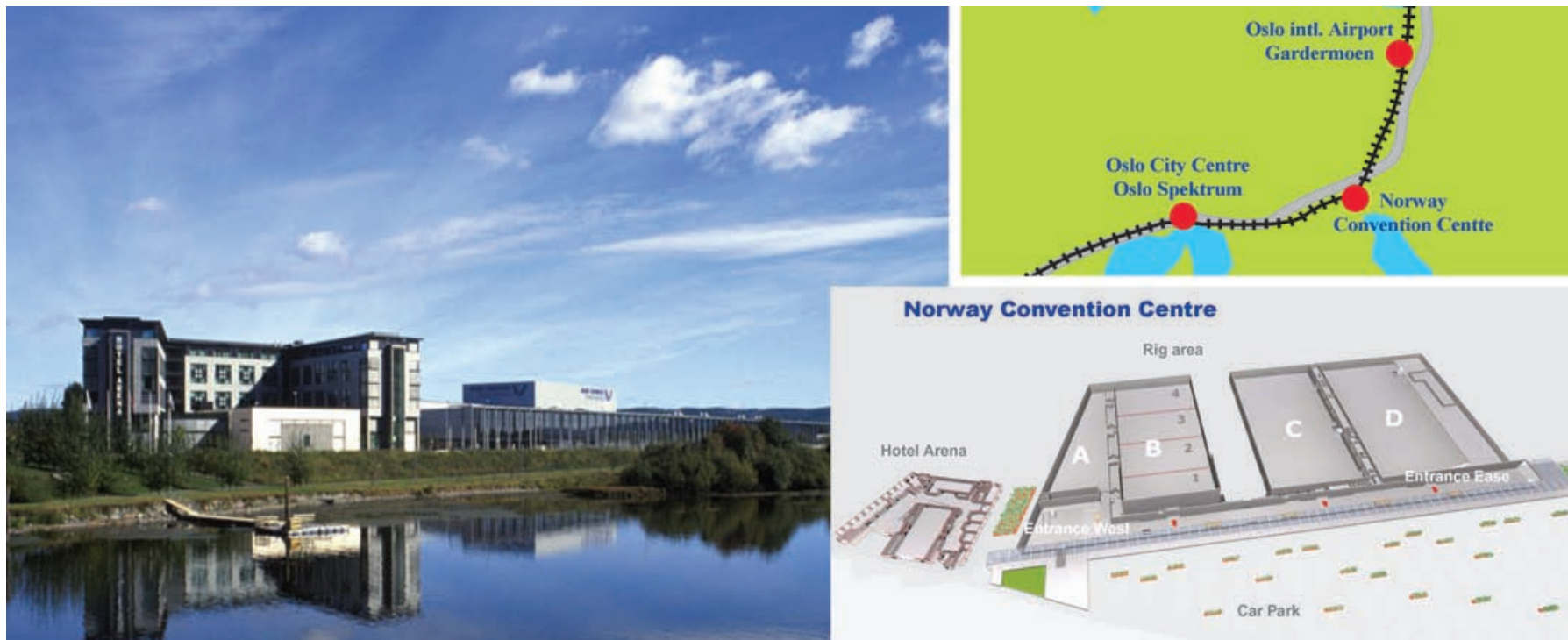

Norway Convention Centre

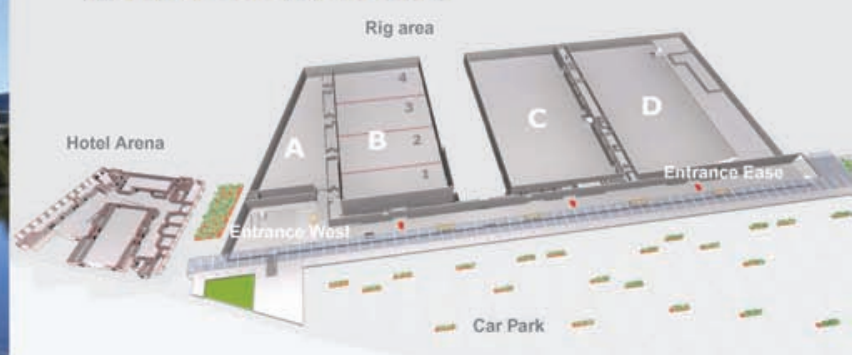

Figure 2 The venue for the 33rd IGC, the Norway Convention Centre, which is located midway between Oslo City Centre and the Gardermoen International Airport, roughly 15 min. train ride from either side. The lower right inset shows the centre outline. Hall B will be used for the "Themes of the Day" and plenary lectures. GeoExpo 2008 and the poster presentations will be located in Hall C, whereas additional lecture halls will be built inside Hall D. 
Table 1 Programme for the "Themes of the day" at the 33rd IGC.

\begin{tabular}{lr|l}
\hline \multicolumn{2}{c|}{ Date } & \multicolumn{1}{c}{ Theme } \\
\hline Thursday & 7 August & Early life and survival of the fittest-Did Darwin get it right? \\
Friday & 8 August & Climate change: past, present, future-What is anthropogenic? \\
Saturday & 9 August & Geohazards—Can society cope? \\
Monday & 11 August & Water, human health and the environment-Is groundwater a hazardous resource? \\
Tuesday & 12 August & Mineral resources in a fast growing global economy-Are there any natural limits? \\
Wednesday & 13 August & The energy race-What will be the future energy mix? \\
Thursday & 14 August & Earth and beyond-From a cosmic perspective. \\
\hline
\end{tabular}

the venue for the opening and closing ceremonies. Lunches (complimentary) are also served in the centre during the Congress.

Hotel accommodation with a wide range of price levels, is offered both in the city centre and the surroundings, as well as near the Oslo International airport, north of the Congress venue.

Transport between the city centre and the venue will be arranged by train and/or buses.

\section{Science programme}

\section{Symposia}

The scientific programme of the Congress was initiated mainly through a "bottom-up process", in which the global geoscience community was invited to propose symposia. This resulted in more than 600 suggestions. The Science Committee (SciCom) reviewed the proposals, merged overlapping proposals and identified and filled "holes" in the programme. This process resulted in a total of about 450 symposia which were presented in the science programme when registration opened on September 1st, 2007. Good suggestions for symposia subsequently have been accepted, with the aim of having as comprehensive a multidisciplinary programme as possible, in accord with the informal title 'Geoscience World Congress 2008'.

Three categories of Symposia are being arranged, referred to as General, Special and Topical, as in previous IGCs. They will run in parallel throughout the Conference. The time allocated to each symposium will be dependent on the number of related contributions (abstracts) received by 29th February 2008. Division of these symposia contributions between oral and poster presentations will depend on the recommendations of the conveners and the capacity of the many parallel sessions.

General Symposia will cover all the main Geoscience disciplines. They are organised in related groups to allow easy navigation within the overall programme. A group of coordinators was selected to coordinate the submission of symposia within broad geoscientific topics. These coordinators also act as convenors for some of the symposia within their topic. Special Symposia at the 33IGC are dedicated to Regional Geology and include all the continents-Africa, Asia, Europe, North America, South America and Oceania (including Australia and New Zealand). Arctic and Antarctic symposia are included within these Special symposia, as are global geological projects. Topical Symposia are of interdisciplinary character and cover a very wide range of subjects that are of particular interest for Earth Science today. They range from basic geoscience to societal issues and managerial-organizational problems. All aspects of the International Year of Planet Earth (IYPE) will have a place amongst these symposia as will the geoscience of the International Polar Year (IPY).

\section{Themes of the day}

Seven themes of importance for society have been chosen for particular priority in the programme. These themes each have a dedicated day of the Congress (Table 1), which is divided into morning and afternoon sessions, separated by a lunch-time plenary lecture. The morning sessions are dedicated to presentations of the geoscientific aspects of the theme. After the "StatoilHydro Lecture", the afternoon sessions will focus on societal, political and economic aspects and the day will end in a panel debate and press conference. All presentations will be given by invited lecturers. Ministers from the Nordic governments are being invited to contribute to the afternoon sessions and participate in the panel debates.

\section{Excursions}

About 50 pre- and post-Congress excursions are being prepared (Figure 3). These cover all the Nordic Countries, including Iceland and the Faeroe Islands. In addition, there are excursions to Svalbard, Greenland, NW Russia and Ukraine. The length of the excursions varies from 2-3 days up to nearly 2 weeks, and the price varies, of course, according to length and location. One-day excursions in the Oslo area will be arranged during the Congress. The prices of excursions have been kept as low as possible, and some of the more expensive ones (e.g., to the High Arctic) are being sponsored to reduce the price for the participants. The excursions cover a wide range of Nordic and Arctic geology, and will also give the participants insight into the natural and cultural heritage of the region.

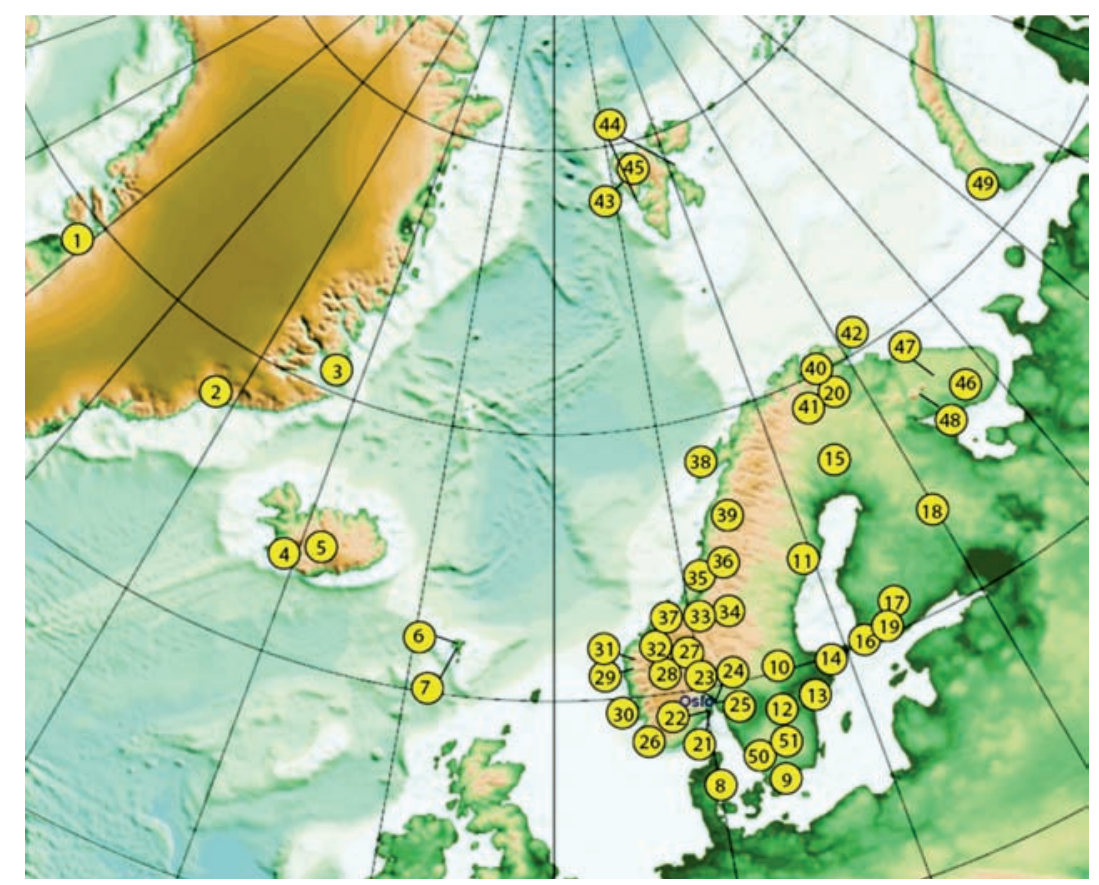

Figure 3 Planned excursions at the 33rd IGC. Some excursions may be cancelled or merged, and updated information is given on the Website (www.33igc.org). The programme also includes excursions to Ukraine and the Urals, not shown in this map. 


\section{Workshops, short-courses, and business meetings}

The 33rd IGC is a meeting place where many activities other than the symposia will take place. A wide range of short (single-day) courses have been proposed. These will be run by experienced lecturers and are designed for all who wish to widen their knowledge of particular subjects. Workshops form another arena, which provide an opportunity for specialists to discuss particular subjects that are less suitable for symposia. These may, for example, include international projects or new technologies that are attracting particular interest. Workshops, short-courses and business meetings are announced on the website, and participants need to register their attendance.

Many of the commissions, projects, and affiliated associations of the International Union of Geological Sciences (IUGS) hold business meetings at IGC. In addition, other associations, companies, etc. have been encouraged to hold their meetings during the Congress. Rooms are provided free of charge. The workshops, shortcourses, and business meetings will primarily be concentrated to Sunday 10 August, but may also be arranged at other times, dependent on the availability of rooms.

\section{The Exhibition "GeoExpo 2008"}

More than 2,500 $\mathrm{m}^{2}$ of the venue are dedicated to the exhibition. Our aim is that the GeoExpo exhibition at the 33rd International Geological Congress should be one of the largest and most valuable exhibitions for all geo-related industry as well as for all governmental and private organisations operating in geosciences. Being located in Norway, we expect many Congress participants to come from the petroleum and mining industry. New frontiers in exploration are being opened in the Arctic areas, with its many environmental and technological challenges. We hope that these issues will be addressed at the GeoExpo, and that the Congress will be the main meeting place to discuss these important topics.

The exhibition will be located in the same hall as the poster presentations (Hall C, Figure 2), and will be a natural meeting point for all participants. Exhibitors will be clustered in "villages" where visitors can scan through geological surveys of the world, universities, science publishers, computer companies, consultancies, oil companies, etc. With the present-day tough competition to attract good young geoscientists, we also expect many companies to use the GeoExpo 2008 as a venue for recruitment.

\section{The social and cultural programme}

We aim at providing an entertaining social and cultural programme for the thousands of participants from all over the world coming to the 33rd IGC. The events, all announced on the website, include opening and closing ceremonies, icebreaker party, an evening in the new Oslo Opera House, a rock/jazz club, and an outdoor barbeque party in the Oslo Botanical Gardens. The cultural programme will introduce the participants to the cultural life in all the five Nordic countries. In addition to the official programme, Oslo is a lively city with numerous bars, restaurants, and music clubs; guides to what is going on in Oslo during the period of the Congress will also be provided. There will be plenty of opportunities to have a good time in Oslo in August 2008, outside of the Congress hours.

\section{Final words}

The IGCs are arranged only every four years. The 33rd IGC, with its wide-ranging and exciting excursion programme, many workshops, short-courses, business meetings, and a varied cultural and social programme is the main Geoscience venue for 2008. The last IGCs have seen a steady increase in the number of participants, and we aim at continuing this trend. Our major goal is not only to provide a forum for the world's geoscientists to present and discuss the latest developments in their own disciplines, but also to focus the World's attention on the importance of Earth Science for Society. Our hope is that the success of the 33rd IGC will encourage participation in the 34 th IGC to be held in Brisbane, Australia in 2012.

\section{References}

Abbate, E., Borieani, A., Giobbi, E., Serra, F., and Zuffa, G.G. (Eds.), 32nd International Geological Congress, Florence - Italy, August 20-28, 2005. General Proceedings. Report from the Organising Committee, 161pp.

Sundquist, B. and Nordlund, C., 2004, Science and honour: The 11th International Geological Congress in Stockholm 1910: Episodes, v. 27, 284-292.

Sørensen, H., 2007, The 21st International Geological Congress, Norden 1960. Episodes Vol. 30, no.2, pp.125-130.

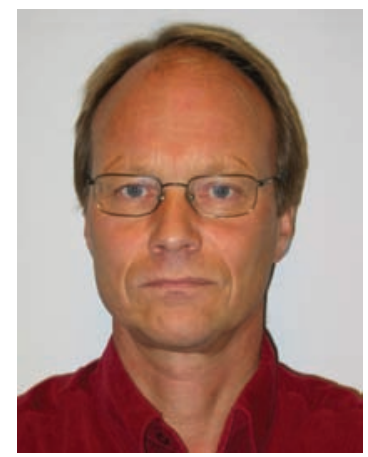

Anders Solheim has his Ph.D from the University of Oslo, 1988. He was with the Norwegian Polar Institute from 1981 to 1998, and had positions as research scientist, section leader, and acting research director. From 1998 to 1999, Solheim was a senior geophysicist in Aker Geo Petroleum Services AS, and from 1999 he has been with the Norwegian Geotechnical Institute (NGI), where he now holds the position as director for the Natural Hazards division. From 2002 through 2006. Solheim had an adjunct professorship at the University Centre in Svalbard (UNIS). Solheim is Secretary General for the 33rd International Geological Congress.

Arne Bjørlykke is Director General at Geological Survey of Norway. From 1984 to 1994 he was professor in geology (mineral resources) at University of Oslo and worked with lead and sulphur isotopes and fluid inclusions in ore geological modeling. Bjørlykke has been chairman of the advisory committee for chemistry, biology and earth sciences in the Norwegian Research Council (NRF), Member of the Petromax board (NRF), President of the Norwegian Academy of Technological Sciences, President in CAETS (International Council of Academies of Engineering and Technological Sciences), Member of Legal and Technical Committee of the International Seabed Authority (ISA), and President of the Organising Committee, $33 r d$ IGC 2008.

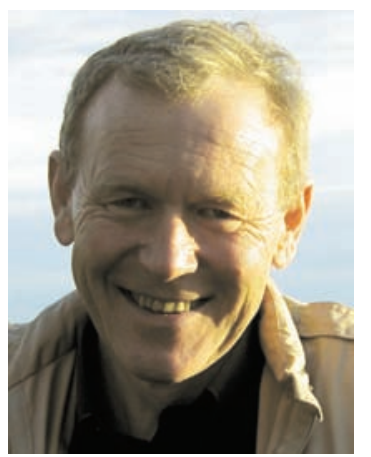

